\title{
EDUCAÇÃO PROFISSIONAL TÉCNICA \\ INTEGRADA AO ENSINO MÉDIO: DESAFIOS \\ DA IMPLANTAÇÃO DE UMA PROPOSTA DE \\ CURRÍCULO INTEGRADO NO \\ IFTM - CÂMPUS PARACATU
}

Nara Moreira*

Gianna Andréia Ferreira Gobbi**

Resumo: O presente artigo decorre da nossa experiência na implantação de um currículo integrado nos Cursos Técnicos de Informática e Eletrônica modalidade integrada ao Ensino Médio - no Instituto Federal de Educação, Ciência e Tecnologia do Triângulo Mineiro (IFTM) - Câmpus Paracatu. Esse artigo pretende também ampliar as discussões acerca das estratégias de integração entre ensino médio e ensino técnico, necessárias à inovação nos processos de ensino-aprendizagem. Faz-se necessária a busca por um currículo que atenda às demandas do mundo do trabalho, bem como da formação omnilateral ${ }^{1}$ dos sujeitos. Diante da amplitude da experiência, verifica-se que há diferentes discursos sobre integração presentes nas atuais políticas e práticas curriculares. Esses diferentes enfoques são interpretados e apropriados e refletem comumente na reinterpretação dos discursos e das próprias práticas docentes.

Palavras-chave: Ensino técnico integrado. Ensino médio. Currículo integrado. 


\title{
THE INTEGRATED TECHNICAL \\ EDUCATION HIGH SCHOOL: CHALLENGES \\ OF IMPLEMENTATION OF A PROPOSED \\ INTEGRADED CURRICULUM IN IFTM - \\ CÂMPUS PARACATU
}

\begin{abstract}
The present article moves from our experience in a implantation of an integrated curriculum in the Informatics and Electronics Technical Courses - modality integrated high school - at the Federal Institute of Education, Science and Technology of Triângulo Mineiro (IFTM) - Câmpus Paracatu. This article also aims to broaden the discussion about the strategies of integration between secondary and technical education, so necessary to innovation in the teaching and learning process. It is necessary to search for a curriculum that meets the demands of the working world, as well as training omnilateral subjects. Given the breadth of experience, it verifies that there are different discourses on integration present in current policies and curriculum practices. These different approaches are interpreted and appropriate and commonly reflect the reinterpretation of discourses and their own teaching practices.
\end{abstract}

Keywords: Integrated technical education. Secondary education. Integrated curriculum. 


\section{Introdução}

Em 2008, o então Centro Federal de Educação Tecnológica (CEFET) - Uberaba mantinha na cidade de Paracatu uma Unidade de Ensino Descentralizada (UNED), com oferta dos cursos técnicos em parceira com o Governo Estadual de Minas Gerais. Com a Lei n. 11.892, de 29 de dezembro de 2008, o CEFET Uberaba, as UNEDs de Paracatu e Ituiutaba e a Escola Agrotécnica Federal de Uberlândia se fundem na criação do Instituto Federal de Educação, Ciência e Tecnologia do Triângulo Mineiro (IFTM). Por força de Lei, passaram a condição de câmpus da nova instituição de forma automática e independente de qualquer formalidade. Assim, o IFTM - Câmpus Paracatu ganha evidência ofertando Cursos Técnicos em Informática e Eletrônica integrados ao Ensino Médio.

Durante o período de três anos (2008 a 2010) de oferta dos cursos técnicos integrados ao ensino médio, havia uma forte fragmentação curricular, com duas partes distintas: ensino médio e ensino técnico. Os cursos eram na realidade concomitantes travestidos de integrados. No período da manhã, os alunos assistiam às aulas referentes às disciplinas propedêuticas, sendo essas em regime anual, com processos avaliativos trimestrais. No período da tarde, eram lecionadas as disciplinas técnicas, em regime semestral, com processos avaliativos bimestrais. Essa adoção pedagógico-estrutural fomentava o pensamento de oferta de dois cursos distintos. O que é sublinhado pela Resolução n. 20/2011, de 29 de março de 2011, que aprova o Regulamento da organização didático-pedagógica dos Cursos de Educação Técnica de Nível Médio do IFTM (2011, p. 27):

Art. 97. No Curso Técnico Integrado ao Ensino Médio em que as unidades curriculares da Base Nacional Comum e 
da Parte Diversificada são oferecidas em regime anual e as do ensino técnico em regime semestral, o sistema de avaliação da aprendizagem, a recuperação, a dependência e a promoção seguirão:

I. para as unidades curriculares ministradas com periodicidade anual, o previsto neste regulamento para o ensino médio em concomitância com os cursos técnicos;

II. para as unidades curriculares que compõem o ensino profissional, ministradas com periodicidade semestral, o previsto para os cursos técnicos concomitantes e subsequentes.

A carga horária do curso era obtida a partir da soma da carga horária total do ensino médio e das disciplinas técnicas. A saber, o Curso Técnico em Eletrônica integrado ao Ensino Médio tinha 4.011,2 horas e Curso Técnico em Informática, também integrado, perfazia um total de 3.680 horas.

Percebia-se a contrariedade ao Decreto n. 5.154/2004, reforçando a dicotomia do projeto pedagógico e sua proposta curricular.

O currículo do curso técnico integrado ao ensino médio deve propiciar a busca pela superação histórica em torno do real papel da escola: formação para a cidadania ou para o trabalho produtivo. A concepção de educação profissional tecnológica baseia-se na intrínseca relação entre cultura, ciência e tecnologia em vistas à formação humana cidadã com a capacidade de manter-se em desenvolvimento.

Sacristán (1991, p. 86-87) destaca que “[...] currículo é a apreensão de todo um sistema de comportamento e valores e não apenas de conteúdo de conhecimentos." Isso implica na análise da interferência das práticas cotidianas em sala de aula no processo de aprender dos alunos. Essa consideração nos remete a um currículo abrangente, entendido como a cultura real: 
[...] que surge de uma série de processos, mais que como um objeto delimitado e estático que se pode planejar e depois implantar; aquilo que é, na realidade, a cultura nas salas de aula fica configurado em uma série de processos: as decisões prévias acerca do que se vai fazer no ensino, as tarefas acadêmicas reais que são desenvolvidas, a forma como a vida interna das salas de aula e os conteúdos de ensino se vinculam com o mundo exterior, as relações grupais, o uso e o aproveitamento de materiais, as práticas de avaliação, etc.

Assim, Pacheco (2011, p. 15) salienta que:

$\mathrm{Na}$ proposta dos Institutos Federais, agregar à formação acadêmica a preparação para o trabalho (compreendendo-o em seu sentido histórico, mas sem deixar de afirmar seu sentido ontológico) e discutir os princípios das tecnologias a ele concernentes dão luz a elementos essenciais para a definição de um propósito específico para a estrutura curricular da educação profissional e tecnológica. O que se propõe é uma formação contextualizada, banhada de conhecimentos, princípios e valores que potencializam a ação humana na busca de caminhos de vida mais dignos.

Em 2010, com a chegada da equipe pedagógica e de professores, nomeados para o quadro permanente de servidores do IFTM, instaura-se o diálogo para uma nova forma de entender a educação profissional técnica integrada ao Ensino Médio. Para compreendermos melhor este processo de implantação de um novo currículo nos cursos técnicos integrados ao ensino médio no IFTM - Câmpus Paracatu é necessário reavivar os decretos n. 2.208/1997 e n. $5.154 / 2004$. 


\section{A influência dos decretos n. 2.208/1997 e n. 5.154/2004 sobre o currículo}

O ensino médio é marcado, historicamente, pelo dualismo, sendo a contradição entre capital e trabalho o dilema crucial de sua identidade. Segundo Frigotto (2010, p. 32):

No Brasil, o dualismo se enraíza em toda a sociedade através de séculos de escravismo e discriminação do trabalho manual. Na educação, apenas quase na metade do século XX, o analfabetismo se coloca como uma preocupação das elites intelectuais e a educação do povo se torna objeto de políticas de Estado. Mas seu pano de fundo é sempre a educação geral para as elites dirigentes e a preparação para o trabalho para órfãos, os desamparados. Esse dualismo toma um caráter estrutural especialmente a partir da década de 1940, quando a educação nacional foi organizada por leis orgânicas.

Com a promulgação da Lei de Diretrizes e Bases da Educação Nacional 9.394/1996, foi expedida uma série de documentos que promoveram uma reforma na educação brasileira. O Projeto de Lei n. 1.603/1996 encontrou resistência dos movimentos de trabalhadores, ONGs, estudantes e sindicatos para regulamentar a educação profissional. Assim, prevendo que o trâmite para aprovação deste PL seria extenso, o governo do presidente Fernando Henrique Cardoso suspendeu o Projeto de Lei n. 1.603/1996 substituindo-o pelo Decreto n. 2.208/1997.

O Decreto n. 2.208/1997 previa regulamentar $\$ 2^{\circ}$ do art. 36 e os artigos 39 a 42 da LDB 9.394/1996, que trata da Educação Profissional e sua relação com o Ensino Médio. A reforma proposta por esse decreto resultou em um modelo dualista, oferecendo uma 
educação propedêutica e uma formação técnico-profissional. Para Kuenzer (1999, p. 135), “[...] esta proposta é conservadora porque retoma a concepção taylorista-fordista que supõe a ruptura entre o saber acadêmico, desvalorizado por não ser prático, e o saber para o trabalho, desvalorizado por não ser teórico.”

Assim a Educação Profissional passa a ter sua organização curricular em módulos com o objetivo de certificar cursos de curta duração. Os módulos se caracterizavam pela terminalidade, formando indivíduos alienados para o trabalho. O Artigo $8^{\circ}$, do Decreto n. 2.208/1997 sublinha:

Art $8^{\circ}$ Os currículos do ensino técnico serão estruturados em disciplinas, que poderão ser agrupadas sob a forma de módulos.

$\$ 1^{\circ}$ No caso de o currículo estar organizado em módulos, estes poderão ter caráter de terminalidade para efeito de qualificação profissional, dando direito, neste caso, a certificado de qualificação profissional.

$\$ 2^{\circ}$ Poderá haver aproveitamento de estudos de disciplinas ou módulos cursados em uma habilitação específica para obtenção de habilitação diversa.

$\S 3^{\circ}$ Nos currículos organizados em módulos, para obtenção de habilitação, estes poderão ser cursados em diferentes instituições credenciadas pelos sistemas federal e estaduais, desde que o prazo entre a conclusão do primeiro e do último módulo não exceda cinco anos.

$\$ 4^{\circ} \mathrm{O}$ estabelecimento de ensino que conferiu o último certificado de qualificação profissional expedirá o diploma de técnico de nível médio, na habilitação profissional correspondente aos módulos cursados, desde que o interessado apresente o certificado de conclusão do ensino médio.

Art $9^{\circ}$ As disciplinas do currículo do ensino técnico serão ministradas por professores, instrutores e monitores selecionados, principalmente, em função de sua experiência profissional, que deverão ser preparados para o magistério, 
previamente ou em serviço, através de cursos regulares de licenciatura ou de programas especiais de formação pedagógica.

Para Frigotto, Ciavatta e Ramos (2010, p. 52), o Decreto n. 2.208/1997 “[...] expressava de forma emblemática a regressão social e educacional sob a égide do ideário neoconservador ou neoliberal e da afirmação e ampliação da desigualdade de classes e o dualismo na educação."

O movimento de revogação do Decreto n. 2.208/1997 e a normatização da articulação entre a educação profissional técnica de nível médio e o ensino médio na forma integrada buscam conduzir para a superação do dualismo existente.

Em 2003, após eleição do presidente Luiz Inácio Lula da Silva, professores e estudiosos da educação profissional reivindicaram a reestruturação da educação técnica e tecnológica, que culminaram na publicação do Decreto n. 5.154/2004. Apesar deste decreto ser fruto de intensas discussões e polêmicas, traz as mesmas contradições do Decreto n. 2.208/1997 e avança apenas no sentido de possibilitar a integração do ensino médio e da educação profissional.

A integração curricular proposta pelo Decreto n. 5.154/2004 é ratificada com o Parecer n. 39/2004, que dispõe da aplicação do referido decreto. O currículo integrado propõe, segundo Frigotto, Ciavatta e Ramos (2010, p. 17-18):

a) que conceba o sujeito como ser histórico-social concreto capaz transformar a realidade em que vive; b) vise à formação humana como síntese de formação básica e formação para o trabalho; c) tenha o trabalho como princípio educativo no sentido de que o trabalho permite 
concretamente, a compreensão do significado econômico, social, histórico, político e cultural das ciências e das artes; d) seja baseado numa epistemologia que considere a unidade de conhecimentos gerais e conhecimentos específicos e numa metodologia que permita a identificação das especificidades desses conhecimentos quanto à sua historicidade, finalidades e potencialidades; e) seja baseado numa pedagogia que vise à construção conjunta de conhecimentos gerais e específicos no sentido de que os primeiros fundamentam os segundos e esses evidenciam $o$ caráter produtivo concreto dos primeiros; f) seja centrado nos fundamentos das diferentes técnicas que caracterizam o processo de trabalho moderno, tendo como eixos o trabalho, a ciência a cultura.

Frigotto, Ciavatta e Ramos (2010, p. 44) analisam que o ensino médio necessita “[...] de consolidação da formação básica unitária e politécnica, centrada no trabalho, na ciência e na cultura, numa relação mediata com a formação profissional específica que se consolida em outros níveis e modalidades de ensino."

McLaren (1997, p. 216) comenta que:

O currículo representa muito mais do que um programa de estudos, um texto em sala de aula ou o vocabulário de um curso. Mais do que isso, ele representa a introdução de uma forma particular de vida; ele serve, em parte, para preparar os estudantes para posições dominantes ou subordinadas na sociedade existente. O currículo favorece certas formas de conhecimento sobre outras e afirma os sonhos, desejos e valores $[. .$.$] .$ 


\section{A proposta de um currículo integrado: desafios e possibilidades}

No início de 2010, com a chegada dos novos servidores do quadro permanente no IFTM - Câmpus Paracatu, a equipe pedagógica e os professores se reuniram com a intenção de discutir sobre o projeto pedagógico dos Cursos Técnicos em Eletrônica e Informática integrados ao Ensino Médio que vigoravam desde 2008. Tais projetos apresentavam inconsistências quanto ao perfil profissional e a matriz curricular, além de pouca articulação entre teoria e prática. Como a equipe acabara de ingressar no serviço público federal, pouco se sabia sobre o projeto da Educação Profissional Técnica integrada ao Ensino Médio proposta a partir do Decreto n. 5.154/2004.

A matriz curricular do Curso Técnico em Informática Integrado ao Ensino Médio para os ingressantes no ano de 2010 é apresentada nas tabelas 1 e 2 . Percebe-se forte segregação entre ensino médio e ensino técnico, com organizações didático-pedagógicas distintas. Cada disciplina é estanque em si mesma.

A tabela 1 apresenta a matriz curricular referente ao Ensino Médio, para os ingressantes no ano de 2010.

É importante salientar que o acréscimo das disciplinas da Base Nacional Comum e de formação técnica não resulta no que chamamos de integrar. De acordo com o Documento-Base do MEC (2007), integrar é compreender o sentido da parte no todo e vice versa, ou seja, considerar a complexidade do todo social. Para o âmbito do currículo integrado que articula a formação básica (nível médio) à formação profissional (ensino técnico), subentende-se que a educação deve ofertar bases para uma formação integral 
EDUCAÇÃO PROFISSIONAL TÉCNICA INTEGRADA AO ENSINO MÉDIO: DESAFIOS

DA IMPLANTAÇÃO DE UMA PROPOSTA DE CURRÍCULO INTEGRADO

NO IFTM - CÂMPUS PARACATU

e adequada as necessidades sociais e humanas.

A tabela 2 expõe a estrutura curricular das disciplinas técnicas. Além de não se consolidar uma única matriz curricular, é notória a ausência de interlocução disciplinar, traduzindo assim na fragmentação do próprio curso.

Tabela 1 - Matriz Curricular do Ensino Médio - Curso Técnico em Informática Integrado ao Ensino Médio

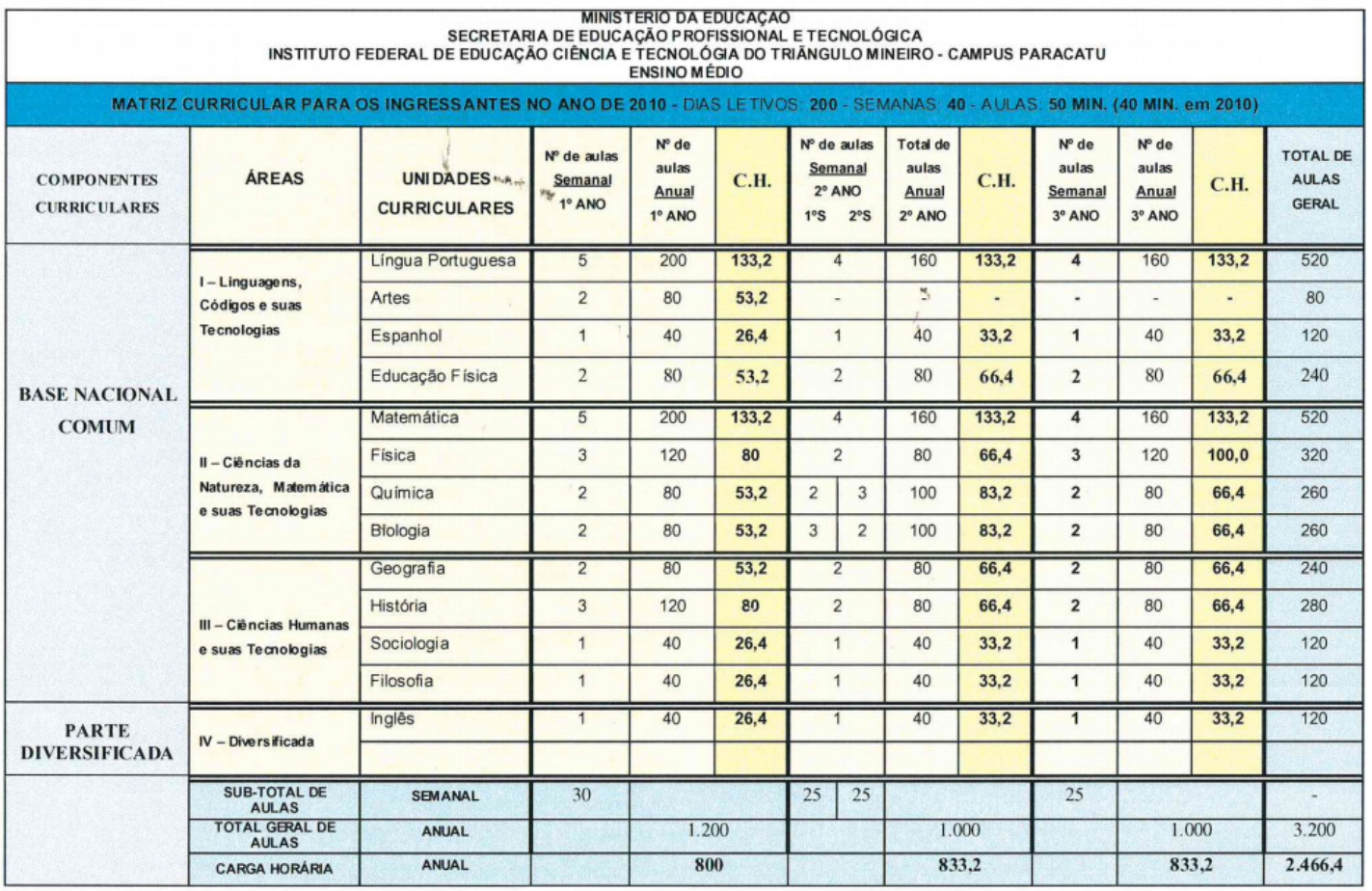


Tabela 2 - Matriz Curricular das disciplinas técnicas - Curso Téc-

nico em Informática Integrado ao Ensino Médio

\section{MATRIZ CURRICULAR - INFORMÁTICA INTEGRADO INGRESSOS EM JANEIRO DE 2010}

\begin{tabular}{|c|c|c|c|c|}
\hline \multicolumn{3}{|c|}{$\begin{array}{l}\text { INSTITUTO FEDERAL DE EDUCAÇĀO, CIÊNCIA E TECNOLOGIA DO } \\
\text { TRIÂNGULO MINEIRO - IFTM - CAMPUS PARACATU }\end{array}$} & \multirow{2}{*}{\multicolumn{2}{|c|}{$\begin{array}{c}\text { CARGA } \\
\text { HORÁRIA } \\
\text { DO CURSO: } \\
\text { 1.213,2 HORAS } \\
\text { Módulo: } \\
20 \text { semanas }\end{array}$}} \\
\hline \multicolumn{3}{|c|}{ CURSO TÉCNICO EM INFORMÁTICA INTEGRADO } & & \\
\hline Componentes Curriculares- $*$ & $\begin{array}{l}\text { No. } \\
\text { Prof. }\end{array}$ & $\begin{array}{c}\text { Aulas/ } \\
\text { Semanas }\end{array}$ & $\begin{array}{l}\text { Total } \\
\text { Aulas }\end{array}$ & $\begin{array}{c}\text { Total } \\
\text { Horas }\end{array}$ \\
\hline \multicolumn{5}{|l|}{ Módulo I - } \\
\hline Informática Bá́sica & 1 & 2 & 40 & 26,4 \\
\hline Português Instrumental & 1 & 2 & 40 & 26,4 \\
\hline Inglês Instrumental & 1 & 2 & 40 & 26,4 \\
\hline Empreendedorismo & 1 & 2 & 40 & 26,4 \\
\hline \multirow[t]{2}{*}{ Álgebra } & 1 & 2 & 40 & 26,4 \\
\hline & TOTAL & 10 & 200 & 133,2 \\
\hline \multicolumn{5}{|l|}{ Módulo II - } \\
\hline OCS & 1 & 4 & 80 & 53,2 \\
\hline Algoritmo & 1 & 6 & 120 & 80 \\
\hline Arquitetura e Organização de Computadores & 1 & 6 & 120 & 80 \\
\hline Ética e Responsabilidade Social & 1 & 1 & 20 & 13,2 \\
\hline & TOTAL & 17 & 340 & 226,4 \\
\hline \multicolumn{5}{|l|}{ Módulo III - } \\
\hline Linguagem Técnica de Programação & 1 & 5 & 100 & 83,2 \\
\hline Banco de Dados & 1 & 4 & 80 & 66,4 \\
\hline Linux & 1 & 3 & 60 & 50 \\
\hline \multirow[t]{2}{*}{ Manutenção de Computadores } & 1 & 4 & 80 & 66,4 \\
\hline & TOTAL & 16 & 320 & 266,4 \\
\hline \multicolumn{5}{|l|}{ Módulo IV - } \\
\hline Programação Visual cliente/servidor & 1 & 5 & 100 & 83,2 \\
\hline Programaçāo para Internet & 1 & 4 & 80 & 66,4 \\
\hline Redes de Computadores & 1 & 4 & 80 & 66,4 \\
\hline \multirow[t]{2}{*}{ Metodologia do Trabalho Científico } & 1 & 1 & 20 & 16,4 \\
\hline & TOTAL & 14 & 280 & 233,2 \\
\hline \multicolumn{5}{|l|}{ Módulo V - } \\
\hline Administração de redes Windows & 1 & 4 & 80 & 66,4 \\
\hline Engenharia de Software & 1 & 3 & 60 & 50 \\
\hline Administração de rede Linux & 1 & 4 & 80 & 66,4 \\
\hline Oficinas Integradas & 1 & 3 & 60 & 50 \\
\hline & TOTAL & 14 & 260 & 233,2 \\
\hline \multicolumn{2}{|l|}{ TOTAIS ACUMULADOS MODULOS $1+\|++1\|+1 \mathrm{~V}+\mathrm{V}$} & 67 & 1340 & $1.093,2$ \\
\hline \multicolumn{3}{|c|}{ ESTÁGIO } & & 120 \\
\hline \multicolumn{3}{|c|}{ CARGA HORÁRIA TOTAL - TÉCNICO EM INFORMÁTICA } & & $1.213,2$ \\
\hline
\end{tabular}


Gramsci (1981, p. 144) afirma que:

Significa que buscamos enfocar o trabalho como princípio educativo, no sentido de superar a dicotomia trabalho manual/trabalho intelectual, de incorporar a dimensão intelectual ao trabalho produtivo, de formar trabalhadores capazes de atuar como dirigentes e cidadãos. A ideia de formação integrada sugere superar o ser humano dividido historicamente pela divisão social do trabalho entre a ação de executar e a ação de pensar, dirigir ou planejar.

Assim, diálogos calorosos ganharam coro para a reestruturação dos projetos pedagógicos dos cursos técnicos integrados ao ensino médio no IFTM - Câmpus Paracatu. Segundo Brook (1999, p. 4) “[...] para que alguma coisa relevante ocorra, é preciso criar um espaço vazio. O espaço vazio permite que surja um fenômeno novo [...]". Apesar de identificada a necessidade de mudanças emergentes nos currículos dos cursos técnicos integrados ao ensino médio, havia uma forte resistência do ensino propedêutico e técnico em trabalharem conjuntamente na implementação desse novo currículo.

Uma comissão foi estabelecida pela Direção Geral do IFTM Câmpus Paracatu, por meio da Portaria n. 25, de 14 de fevereiro de 2011, com o objetivo de conduzir os processos de estudo, análise, viabilidade e sistematização de um documento contendo a proposta de criação de curso de Ensino Técnico Integrado, deu início aos trabalhos de sensibilização da comunidade escolar.

Tal comissão fez um levantamento de algumas situações que foram analisadas como interferência na efetivação de um currículo integrado, no atual modelo proposto pelo IFTM - Câmpus Paracatu, dentre eles: 
- fragmentação curricular, necessitando maior integração de conhecimentos gerais e específicos;

- segregação entre ensino médio e ensino profissional, visto que os cursos de Informática e Eletrônica seguem o regime anual para as disciplinas propedêuticas e regime semestral para as disciplinas profissionalizantes;

- carga horária total dos cursos excessiva, sendo de 4.013,2h para o curso técnico em Eletrônica integrado ao ensino médio e $3.680 \mathrm{~h}$ para o curso técnico em Informática integrado ao ensino médio; - grande parte dos alunos procura um ensino médio de qualidade e não um ensino profissionalizante, gerando maior dedicação à parte propedêutica, deixando em segundo plano as disciplinas profissionalizantes, o que favorece a dualidade entre formação básica e formação profissional; e

- as disciplinas dos cursos técnicos integrados ainda não se condensam num projeto unitário tendo o trabalho como o primeiro fundamento da educação como prática social.

Outra situação também mencionada e que demanda análise é o fato de as aulas acontecerem em período integral - 7h05min às $11 \mathrm{~h} 30 \mathrm{~min}$ e de $13 \mathrm{~h}$ às $16 \mathrm{~h} 30 \mathrm{~min}$, exceto na sexta-feira (7h05min às $11 \mathrm{~h} 30 \mathrm{~min}$ ), tendo como queixa principal, por parte dos alunos, a falta de tempo suficiente para se dedicarem aos estudos com mais afinco.

O grupo composto por trinta docentes, sendo 18 licenciados (60\%) e 12 bacharéis (40\%), de maneira geral, acreditava que não havia um trabalho integrado entre as disciplinas da base nacional comum e as técnicas. Eram realizados alguns projetos interdisciplinares entre dois ou três professores, mas nada que configurasse 
um trabalho efetivo de integração curricular. Muitos desses professores estavam demasiadamente preocupados com o seu conteúdo, comprometidos com o vestibular e com a empregabilidade, isolando suas disciplinas.

A carga horária excessiva dos professores - média de 22 aulas/ semana - adicionada a projetos de pesquisa e extensão impedia o encontro regular da equipe para momentos de estudo, discussão e reflexão da prática pedagógica. Nas reuniões se falava da reestruturação dos projetos pedagógicos, visto que o modelo vigente, ano de 2010, atendia a um ensino meramente transmissivo de conteúdos.

Assim, por intermédio de grupos menores, os professores definiram o perfil profissional dos Cursos Técnicos em Informática e Eletrônica integrados ao Ensino Médio. Em seguida, os docentes analisaram os conteúdos considerados requisitos para o trabalho inicial com as turmas. A partir da listagem desses conteúdos, os professores esquematizaram um plano de trabalho de maneira a articular conhecimentos entre as disciplinas que culminem em aprendizado significativo. $\mathrm{O}$ desafio era criar uma matriz curricular integrada, constituída pelos eixos do trabalho, ciência e cultura, de caráter interdisciplinar.

Segundo Arroyo (1998, p.31):

Situar a relação escola-trabalho-formação do trabalhador no âmbito das relações sociais na escola e na produção significa ver a educação como prática social e cultural, como relação humana e como ação-intervenção política e cultural que mexe com aspirações, valores, pensamento, enfim, com sujeitos humanos que pensam e têm suas aspirações. Processos extremamente complexos que exigem um olhar global. 
Para elucidar parâmetros de movimento no desenho do currículo integrado, utilizou-se os quesitos abaixo relacionados por Ramos (2010, p. 122-3):

1 - Problematizar fenômenos; fatos e situações significativas e relevantes para compreendermos o mundo em que vivemos, bem como processos tecnológicos da área profissional para a qual se pretende formar; como objetos de conhecimento, buscando compreendê-los em múltiplas perspectivas: tecnológica, econômica, histórica, ambiental, social, cultural etc.

2 - Explicitar teorias e conceitos fundamentais para a compreensão do(s) objeto(s) estudado(s) nas múltiplas perspectivas em que foi problematizada e localizá-los nos respectivos campos da ciência (áreas do conhecimento, disciplinas científicas e/ou profissionais), identificando suas relações com outros conceitos do mesmo campo (disciplinaridade) e de campos distintos do saber (interdisciplinaridade).

3 - Situar os conceitos como conhecimentos de formação geral e específica, tendo como referência a base científica dos conceitos e sua apropriação tecnológica, social e cultural.

4 - A partir da focalização dos conceitos e das múltiplas relações, organizar os componentes curriculares e as práticas pedagógicas, visando corresponder, nas escolhas, nas relações e nas realizações, ao pressuposto da totalidade do real como síntese de múltiplas determinações.

Na nova proposta, sugeriu-se a inserção da disciplina de "Projetos Integradores" visando o fomento da articulação dos conhecimentos adquiridos pelo aluno durante o período letivo, culminando na apresentação de um protótipo ou projeto orientado por um professor.

Apesar do trabalho de formatação dos cursos técnicos em Informática e Eletrônica integrados ao Ensino Médio ainda não 
esteja finalizado, é importante salientar que todo esse trajeto percorrido pela equipe pedagógica e docentes gerou uma vontade de fazer educação de uma maneira mais abrangente. É a possibilidade de enxergar cada aluno com um novo olhar, pois, de alguma maneira, estamos fazendo diferença na vida de cada um deles.

\section{Considerações finais}

Diante dos desafios impostos para a concretização de um currículo efetivamente integrado, apresentamos a nossa experiência na implantação do mesmo, na necessidade de dividir com demais instituições o processo que está sendo percorrido e contribuir para estudos futuros.

A formação disciplinar fragmentada e o ensino transmissivo e conteúdista de interface alienante estão sendo superados a partir de uma análise criteriosa e democrática, a fim de alargar o conceito de fazer educação em nossa instituição.

Nesse sentido, Lodi (2006, p.14) afirma que:

A oferta de educação profissional integrada às diferentes formas de educação, ao trabalho, à ciência e à tecnologia, estratégia para o desenvolvimento socioeconômico nacional, revela-se um produto de construção coletiva, articulada institucionalmente e em sintonia com a demanda de trabalho.

Portanto, implica em compreender essa revolução cotidiana, por meio da prática do diálogo no interior da escola, visto que o currículo integrado possui dimensões políticas amplas. Além disso, é necessário incentivar os professores à inovação, buscando a 
integração de disciplinas e temas em vistas a um novo caminho para a Educação Profissional Técnica Integrada ao Ensino Médio. Há uma concepção social, política e ideológica envolta na resistência dos profissionais à mudança em suas práticas pedagógicas.

A superação da visão fragmentária, reprodutivista e mecanicista da educação advêm da necessidade de se colocar o sujeito no centro da organização do trabalho educativo e pedagógico, visando à formação omnilateral. Na experiência de construção do currículo integrado no IFTM - Câmpus Paracatu percebeu-se alguns aspectos determinantes para o alcance da consolidação do currículo integrado. A falta de suporte técnico, que inviabilizou o contato com experiência externa e pesquisadores na área; pouca infraestrutura material e pedagógica, visto que a instituição possui apenas três anos de atuação e não se encontra devidamente equipada e pouco investimentos na formação docente, voltada para a área específica do currículo integrado. Apesar dessas variáveis que interferem no trabalho, é inegável a vontade da mudança. Essa reorganização é um processo dinâmico e participativo a fim de assegurar a eficiência para atingir os objetivos da aprendizagem.

Faz-se necessária a articulação com outras instituições que também se encontram no processo de reestruturação de seus currículos integrados, a fim de que essa troca de experiências resulte positivamente nos resultados alcançados. $\mathrm{O}$ assunto currículo integrado, ao mesmo tempo que se faz instigante, é complexo. Várias instituições buscam respostas que se consolidem em um projeto pedagógico verdadeiramente integrado e alargar essa comunicação unilateral é imprescindível para a execução e fortalecimento de uma educação emancipadora. 


\section{Referências}

ARROYO, M. Trabalho-educação e teoria pedagógica. In: FRIGOTTO, G. Educação e crise do trabalho: perspectivas de final de século. 2. ed. Petrópolis: Vozes, 1998.

BROOK, Peter. A porta aberta. Rio de Janeiro: Civilização Brasileira, 1999.

BRASIL/MEC/SETEC. Educação Profissional Técnica de Nível Médio Integrada ao Ensino Técnico: Documento Base. Brasília: Ministério da Educação, 2007.

BRASIL. MINISTÉRIO DA EDUCAÇÃO. Decreto n. 2.208/1997. Regulamenta o $\$ 2{ }^{\circ}$ do art. 36 e os arts. 39 a 42 da Lei n. 9.394, de 20 de dezembro de 1996, que estabelece as diretrizes e bases da educação nacional. Brasília, 1997.

Decreto n. 5154, de 23 de julho de 2004. Regulamenta o $\$ 2^{\circ}$ do art. 36 e os arts. 39 a 41 da Lei n. 9.394, de 20 de dezembro de 1996, que estabelece as diretrizes e bases da educação nacional, e dá outras providências. Brasília, 2004.

. Lei n. 11.892 de 29 de dezembro de 2008. Institui a

Rede Federal de Educação Profissional, Científica e Tecnológica, cria os Institutos Federais de Educação, Ciência e Tecnologia, e dá outras providências. Brasília, 2008.

FRIGOTTO, Gaudêncio; CIAVATTA, Maria; RAMOS, Marise (Orgs.). Ensino Médio Integrado: concepções e contradições. 2. ed. São Paulo: Cortez, 2010.

GRAMSCI, Antonio. La alternativa pedagógica. Barcelona: Editorial Fontamara, 1981.

LODI, Lúcia Helena. Ensino Médio integrado: uma alternativa de educação inclusiva. In: Ensino Médio Integrado à educação profissional: Integrar para quê? Brasília: Ministério da Educação; Secretaria da Educação Básica, 2006. 
MCLAREN, P. A vida nas escolas: uma introdução à pedagogia crítica nos fundamentos da educação. Porto Alegre: Artes Médicas, 1997.

PACHECO. E. (Org.). Institutos Federais: uma revolução na educação profissional e tecnológica. Brasília: Moderna, 2011.

IFTM. Resolução n. 20/2011, de 29 de março de 2011, que aprova o Regulamento da organização didático-pedagógica dos Cursos de Educação Técnica de Nível Médio do IFTM - Instituto Federal de Educação, Ciência e Tecnologia do Triângulo Mineiro. Uberaba: 2011.

ROMÃO, José Eustáquio. O ensino médio e a omnilateralidade: educação profissional no século XXI. EccoS, São Paulo, v. 12, n. 1, p. 27-49, jan./jun. 2010.

SACRISTÁN, J. G. O currículo: uma reflexão sobre a prática. Porto Alegre: Artmed, 1991.

\section{Notas}

* Pedagoga - Instituto Federal de Educação, Ciência e Tecnologia do Triângulo Mineiro - Câmpus Paracatu. E-mail: <naramoreira@iftm.edu.br>.

${ }^{* *}$ Pedagoga - Instituto Federal de Educação, Ciência e Tecnologia do Triângulo Mineiro - Câmpus Paracatu. E-mail: <giannagobbi@iftm.edu.br>.

${ }^{1} \mathrm{O}$ conceito de omnilateralidade advém de Marx, correspondendo à concepção "[...] de que o ser humano deve ser integralmente desenvolvido em suas potencialidades, através de um processo educacional que leve em consideração a formação científica, a política e a estética, com vistas à libertação das pessoas [...]." (ROMÃO, 2010, p. 1). 